\title{
Ignoring functional and phylogenetic features masks the edge influence on ground beetle diversity across forest-grassland gradient
}

\author{
Tibor Magura \\ Department of Ecology, University of Debrecen, Egyetem sq. 1, H-4032 Debrecen, Hungary
}

\section{A R T I C L E IN F O}

Article history:

Received 26 July 2016

Received in revised form 25 October 2016

Accepted 27 October 2016

Available online xxx

Keywords:

Edge effect

Functional diversity

Functional-phylogenetic diversity

Functional traits

Phylogenetic diversity

Phylogenetic relatedness

Rao's quadratic entropy

\begin{abstract}
A B S T R A C T
There is an increased species richness and species diversity at the edges of forest-grassland mosaics. Taxonomic diversity, however, provides little information on the function or evolutionary history of species, although such is critical in biodiversity studies. The objective of this research was to compare the taxonomic, functional and phylogenetic diversities in ground beetles (Carabidae) across an edge gradient between native forest and natural grassland. Natural forest edges contain diverse and abundant resources and microhabitats; therefore I hypothesised that all three types of diversity will be higher in the forest edge compared to both neighbouring habitats. Taxonomic diversity was strongly affected by an asymmetrical species dispersal between the neighbouring habitats. Many more forest species were found in the grassland (at $50-60 \mathrm{~m}$ from the edge) than grassland species in the forest interior (at 50-60 m from the edge). Accordingly, taxonomic diversity was significantly the highest in the grassland, while there was no significant taxonomic diversity difference between the forest edge and the interior. Functional and phylogenetic diversities were also influenced by this asymmetrical species dispersal, producing the highest values in the grassland. The natural forest edge with high structural complexity and heterogeneity offers microhabitats for both grassland and forest species, but also for edge-associated species. Additionally, forest edge hampers the passing of grassland species into the forest interior. As a consequence, in the forest edge distantly related species with different functional traits coexisted, while closely related species, characterised by similar functional traits inhabited the forest interior, causing significantly higher functional and phylogenetic diversity at the forest edge compared to the interior. I conclude that the inclusion of the functional and phylogenetic features of the assemblages may bring about important insights into the mechanisms behind edge responses.
\end{abstract}

(C) 2016 Published by Elsevier Ltd.

\section{Introduction}

Transitional zones between landscape units are key elements in landscapes (Forman and Godron, 1986). Ecotones are transitional zones between adjacent ecological systems, having a set of characteristics uniquely defined by spatial and time scales and by the strength of the interactions between adjacent ecological systems (Turner et al., 2001). Ecological systems include commonly described hierarchical entities such as demes, populations, communities, ecosystems, landscapes and biomes. Thus, ecotones can be defined at various hierarchical levels, from population to the biosphere; and at various spatial scales, from a few centimetres to thousands of kilometres (Hansen et al., 1992).

Habitat edge is a type of ecotone, interpreted at the community level and the meso-spatial scale. At the habitat edge, as a result of located at or near the border between two habitats, environmental conditions are altered and become substantially different from those of the adjacent habitats (Ewers and Didham, 2006). These changes constitute the abiotic edge effect (Murcia, 1995). These altered abiotic conditions have direct impact on the abundance and distribution of species, causing the direct biological edge effect (Murcia, 1995), which, in turn cause changes in species interactions (predation, her-

Email address: maguratibor@gmail.com (T. Magura) bivory, parasitism, competition, pollination), forming the indirect biological edge effect (Murcia, 1995).

Forest edge is one of the most common habitat edges within terrestrial landscapes (Murcia, 1995). Species richness is higher in the forest edges than in the adjoining habitats because of the variety of resources and microhabitats available near such edges, which was recognised already at the beginning of the 20th century (Clements, 1905), and became ingrained in the modern ecological literature (Odum, 1971). Since then, forest edges have been the focus of both ecological studies and conservation efforts, because the progressive fragmentation of forests has led to an increase in forest edges (Murcia, 1995); in other areas they have disappeared due to recent afforestations (Saunders et al., 1991). Most of the studies on forest edges have focused on the direct biological edge effect, on the changes in abundance and distribution of species near the forest edges (e.g. Baker et al., 2015; Bogyó et al., 2015; Lövei et al., 2006; Tóthmérész et al., 2014).

Ground-dwelling beetles are frequently used taxa for testing the direct biological edge effect because they are taxonomically well known, common in most terrestrial habitats, and can easily be collected using standard methods (Gerlach et al., 2013). However, published results on the direct biological edge effect on ground-dwelling beetles are rather inconsistent. Several papers reported elevated abundance and/or species diversity near the edges compared to the forest interior (e.g. Langhans and Tockner, 2014; Ohwaki et al., 2015; 
Sarthou et al., 2014; Tóthmérész et al., 2014), while other studies failed to observe any increase in these parameters (e.g. Baker et al., 2015; Barnes et al., 2014; Brigić et al., 2014; Filgueiras et al., 2015; Taboada et al., 2004).

All of the above studies on direct biological edge effect on ground-dwelling beetles have focused on taxonomic diversity (species richness and/or species diversity). Taxonomic diversity, however, contains little information on the function or evolutionary history of species, although such information is critical in biodiversity studies (Swenson, 2011, 2013). Currently, a more comprehensive approach to studying biodiversity has emerged. This approach considers the taxonomic, functional and phylogenetic components of biodiversity (Swenson, 2011).

Functional traits influence the ability of species to utilise resources, disperse, reproduce and sustain viable populations (Magura et al., 2015; Violle et al., 2007). Therefore, the functional trait-based analysis has great explanatory potential concerning the mechanisms controlling community responses to environmental change (Kleyer et al., 2012; Spake et al., 2016) and ecosystem functioning (Díaz et al., 2007; Gagic et al., 2015; Laliberte et al., 2010; Vandewalle et al., 2010). Recent studies on plants (Apaza-Quevedo et al., 2015; Benchimol and Peres, 2015; Ma and Herzon, 2014), birds (Barbaro et al., 2014; Saavedra et al., 2014), and mammals (Luza et al., 2015) started to use functional traits to quantify functional diversity in forest edges compared to interiors. However, similar analyses on invertebrates seem to be missing.

Phylogenetically closely related species share many morphological and ecological traits through their common origin and evolutionary history (Webb et al., 2002), but can also have different traits because of adaptive radiation (Schluter, 2000). Consequently, phylogenetic relatedness among species with similar traits may be different, and incorporating the phylogenetic relatedness of constituting species to describe and understand community composition is a crucial aspect in community ecology and biodiversity research (Cadotte et al., 2010). The recognition of the importance of phylogenetic diversity in edge research is increasing, and researchers have started to consider phylogenetic diversity across forest edge gradients (for plants: Benítez-Malvido et al., 2014; Dodonov et al., 2014; Peralta et al., 2015; Santos et al., 2010; for mammals: Luza et al., 2015). Studies on phylogenetic diversity of invertebrates across forest edges are rare: there is only one paper studying this aspect of biodiversity on lepidopteran larvae (caterpillars) and their parasitoids across an edge gradient between native and plantation forests (Peralta et al., 2015).

The objective of this work is to compare the taxonomic, functional and phylogenetic diversities in ground beetle (Coleoptera: Carabidae) assemblages across an edge gradient between native forest and natural grassland. Previous studies on ground beetles reported higher taxonomic diversity in grasslands than forests (Brigić et al., 2014; Koivula et al., 2004; Lacasella et al., 2015; Magura et al., 2001; Roume et al., 2011), and elevated taxonomic diversity at forest edges (Lacasella et al., 2015; Magura, 2002; Tóthmérész et al., 2014). Based on these results, I hypothesised that (1) taxonomic diversity will be higher in the grassland and at the forest edge compared to the forest interior. Because of the diverse and plentiful resources and microhabitats in forest edges (Cadenasso et al., 2003a, 2003b; Harper et al., 2005), several species with different functional traits and several distantly related species could coexist at the forest edge. I therefore hypothesised that the forest edge, given its high habitat heterogeneity, also should have (2) higher functional diversity and (3) higher phylogenetic diversity of ground beetles compared to the neighbouring habitats in either direction.

\section{Material and methods}

\subsection{Study area}

The study was performed in the eastern part of the northern Hungarian mountains, part of the Aggtelek National Park $\left(48^{\circ} 31^{\prime} \mathrm{N}\right.$, $20^{\circ} 31^{\prime} \mathrm{E}$ ). In this region the most extensive native forest association is oak-hornbeam (Querco-Carpinetum), with moderately dry grassland patches embedded within the forested landscape matrix. Three grassland-forest edge-forest interior sites were chosen, located at minimum $150 \mathrm{~m}$ from each other. The sizes of the grasslands and forests were similar (10-15 ha), and were large enough to support characteristic ground beetle assemblages (Mader, 1984). The studied forest stands were unmanaged, 60-year-old oak-hornbeam forests, with closed canopies, a dense leaf litter layer, but moderate herbaceous and shrub layers. The studied forest edges were maintained by natural processes, and had a stratified horizontal structure. The shrub and sapling zone towards the forest interior consisted mainly of Carpinus betulus, Corylus avellana, Prunus spinosa, and Quercus petreae, and there was a dense perennial herb layer towards the neighbouring grassland. Forest edges were oriented eastwards. The studied, unmanaged grassland patches were moderately dry grasslands (Polygalo majori-Brachypodietum pinnati) with dense herbaceous vegetation dominated by Brachypodium pinnatum, Polygala major, Carex montana, Betonica officinalis and Adonis vernalis.

\subsection{Sampling design}

Ground beetles were sampled by pitfall traps. At each site, six trap lines were positioned along a transect centred on and perpendicular to the forest edge. Trap lines were minimum $10 \mathrm{~m}$ apart from each other to provide statistically independent samples and true replicates (Digweed et al., 1995). Two trap lines parallel to the edge were placed along the forest edge in the shrub and sapling zone (at $5 \mathrm{~m}$ from the tree line towards the forest interior) and in the perennial herb layer (at $5 \mathrm{~m}$ from the tree line towards the grassland). The other four trap lines were located in the forest interior and in the grassland patch, with traps at $50 \mathrm{~m}$ and $60 \mathrm{~m}$ from the edge. Altogether, there were 2 trap lines in the forest interior, the edge and the grassland. Each of these trap lines had 7 traps spaced $2 \mathrm{~m}$ apart, with a total of 42 traps per site. In total, 126 pitfall traps were installed ( 3 sites $\times 42$ traps; see Fig. S1). Traps consisted of $100 \mathrm{~mm}$ diameter plastic cups (volume $500 \mathrm{ml}$ ) and contained about $200 \mathrm{ml} 70 \%$ ethylene glycol as a killing-preserving solution and a drop of detergent to break the surface tension. Pitfall traps were protected by fiberboard from litter and rain. Trapping period covered the snow-free season (from March to November), and samples were collected monthly. For evaluation, pitfall trap catches along each trap line were combined for the whole sampling period, resulting in 18 data sets. All ground beetles caught were identified to species using standard keys (Hůrka, 1996).

\subsection{Calculation of diversity measures}

Measuring taxonomic diversity, the rarefied species richness (expected number of species for a given number of randomly sampled individuals), the total species richness, the Shannon and Simpson diversity indices (Magurran, 2004), the species richness of forest-associated, generalist and open-habitat-associated ground beetle species were calculated for each trap line. Rarefied species richness was calculated for a random subsample containing 100 individuals $(90 \%$ of the smallest trap-line sample). The collected species were classified 
into habitat affinity categories (forest, generalist or open-habitat species) using literature sources (Hůrka, 1996).

Functional traits related to morphology, reproduction, dispersal and resource use were selected a priori (see Spake et al., 2016). Life-history traits (body size, wing morphology, mode of overwintering, daily activity and diet) and ecological traits (habitat affinity and humidity preference) were collated (Table S1) using published data (Hůrka, 1996; Gerisch, 2014; Koch, 1989; Larochelle, 1990). Rao's quadratic entropy $(Q ;$ Rao, 1982) was calculated for each trap line to measure the distance-based functional diversity (Botta-Dukát, 2005):

$$
Q=\sum_{i=1}^{S} \sum_{j=1}^{S} d_{i j} p_{i} p_{j}
$$

where $S$ is the number of ground beetle species in a trap line; $d_{i j}$ is the difference between the $i$-th and $j$-th species based on functional traits $\left(d_{i j}=d_{j i}\right.$ and $\left.d_{i i}=0\right) ; p_{i}$ and $p_{j}$ are the relative abundance of the $i$-th and $j$-th species in a trap line.

Distances between species based on functional traits $\left(d_{i j}\right)$ were calculated using Gower's distance metric. This metric allows the calculation of distances among species for a mixture of continuous, ordinal, and categorical variables, and can handle missing trait values (Laliberte and Legendre, 2010). All calculations were made using the $\mathrm{R}$ version 3.2.2 (R Core Team 2013). Gower's distance was computed using the StatMatch package (D'Orazio et al., 2006), and Rao's quadratic entropy was calculated with the SYNCSA package (Debastiani and Pillar, 2012).

Phylogenetic diversity was expressed as abundance-weighted mean pairwise distances between species (Tucker et al., in press) using the Rao's quadratic entropy (Izsák and Papp, 2000) for each trap line. Distance between species $\left(\mathrm{d}_{\mathrm{ij}}\right)$ was based on the branch length to the common ancestor of the phylogenetic tree published by Beutel et al. (2008). Branch length of a phylogenetic tree is commonly used to express phylogenetic relatedness (e.g. Heikkala et al., 2016). Phylogenetic diversity expressed by the Rao's quadratic entropy was calculated using the SYNCSA package (Debastiani and Pillar, 2012) in the R 3.2.2 environment (R Core Team, 2013).

Functional traits and phylogeny may provide different and complementary information about species differences. Recently, Cadotte et al. (2013) proposed an approach to integrate the information provided by traits and phylogenetic information: to measure species differences, the distances between species in trait-space and the distances between species in the phylogenetic-space should be combined as functional-phylogenetic distance (FPDist; Cadotte et al., 2013):

$$
\text { FPDist }=\left(a \text { PDist }{ }^{p}+(1-a) F D i s t^{p}\right)^{1 / p}
$$

where PDist is the phylogenetic distance; FDist is the functional distance, $p$ is an integer to ensure nonlinearity, while $a$ is the weighting parameter, which determines the contribution of PDist and FDist to FPDist. When $a=1$, FPDist only includes phylogenetic distance and when $a=0$, FPDist only includes functional distance.

I calculated the functional-phylogenetic distance by combining the Gower distance matrix between species based on the studied functional traits (functional distance) and the distance matrix based on the branch lengths of the phylogenetic tree (phylogenetic distance). FPDist was calculated using $a=0.5$, ensuring the equal contribution of PDist and FDist to FPDist . To obtain an Euclidean distance from the combined functional and phylogenetic distances, $p=2$ was used (Cadotte et al., 2013). Rao's quadratic entropy, calculated using the functional-phylogenetic distance matrix for each trap line, provided a measure of functional-phylogenetic diversity. Calculations were made using the SYNCSA package (Debastiani and Pillar, 2012 ) in the R 3.2.2 environment (R Core Team, 2013).

Functional and phylogenetic distinctness (expressed as the average distances between species based on the studied functional traits, and on the branch length of the phylogenetic tree) were also calculated for the studied habitat types.

\subsection{Statistical analyses}

Generalized linear mixed-effects models (GLMMs) were used to test differences in the abundance and diversity measures between the studied habitat types (forest interior, forest edge, grassland) at the trap line level. In the models, the habitat type was used as fixed factor; while the spatial replicate (site) was entered as random factor. Abundance and diversity measures (taxonomic diversity, functional diversity, phylogenetic diversity and functional-phylogenetic diversity) were the response variables in the models. Count data (abundance and species richness) were assumed to follow a Poisson distribution, while the other diversity measures were modelled using a Gaussian distribution (with log-link function; Zuur et al., 2009). GLMMs were also used to test differences in the functional and phylogenetic distinctness between the studied habitat types. Habitat type was used as fixed factor. The response variables (functional and phylogenetic distinctness) were assumed to follow a Gaussian distribution (also with log-link function; Zuur et al., 2009). When the overall GLMMs revealed a significant difference between the means, a Tukey test for multiple comparisons among means was performed. GLMM analyses were done with the lme4 package (Bates et al., 2015) in the R 3.2.2 environment ( $\mathrm{R}$ Core Team, 2013).

\section{Results}

A total of 4339 ground beetles belonging to 40 species were trapped during the study. This included 862 individuals of 37 species in the grasslands, 1267 individuals of 23 species at the forest edges, and 2210 individuals of 18 species in the interiors. The most numerous species was Abax parallelepipedus; with 1521 individuals (35.1\% of the total catch) (Table S1).

The total number of individuals was the highest in the forest interior, but did not differ significantly between the forest edge and the grassland (Fig. S2 and Table S2). Both the rarefied species richness and the total number of ground beetle species peaked in the grassland and were significantly lower in forest edge and interior (Figs. 1 and S2, Table S2). An opposite trend was observed for the number of forest specialist species: their species number was lower in the grassland than in the other two habitat types (Fig. 1 and Table S2). The number of both generalist and open-habitat species were higher in the grassland than in the other habitat types (Fig. 1 and Table S2). Similarly, both the Shannon and the Simpson diversity indices were higher in the grassland than in the forest edge or the interior (Fig. 2 and Table S2).

The functional diversity decreased from the grassland across the forest edge towards the forest interior (Fig. 3 and Table S2). The average functional distinctness, based on the studied traits, also decreased from the grassland across the forest edge towards the interior (grassland: 0.5294, edge: 0.4547 , forest interior: 0.3455; Table S2), suggesting that trait divergence was the highest in the grassland, moderate at the edge, and lowest in the interior. 


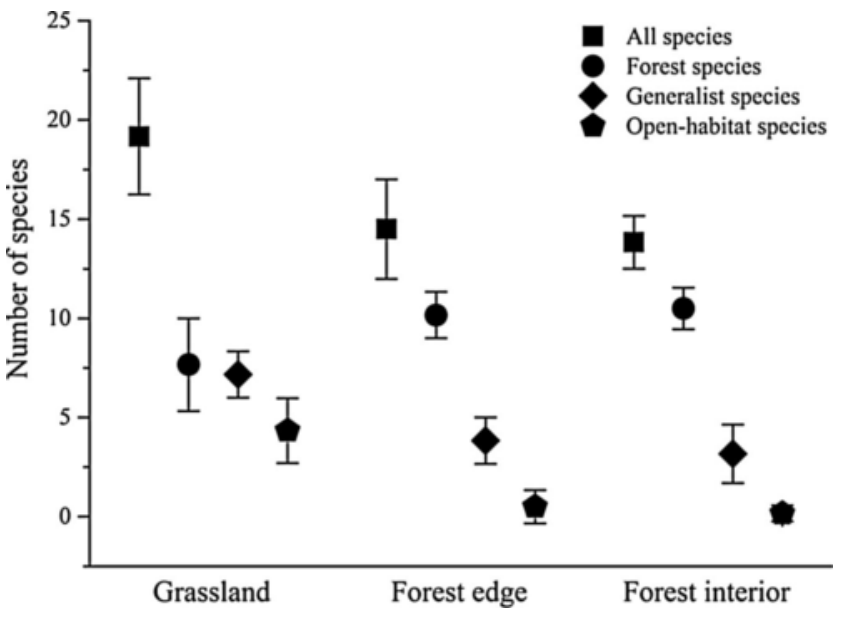

Fig. 1. Mean total number of ground beetle species, and the mean number of forest, generalist and open-habitat ground beetle species $( \pm \mathrm{SD})$ across the studied edge gradient between native forest and natural grassland. Total number of species, number of generalist and open-habitat species were significantly the highest in the grassland, while number of forest species was significantly the lowest in the grassland $(\mathrm{p}<0.05)$, and there was no significant difference between the forest edge and the forest interior $(p>0.05)$ by Tukey test.

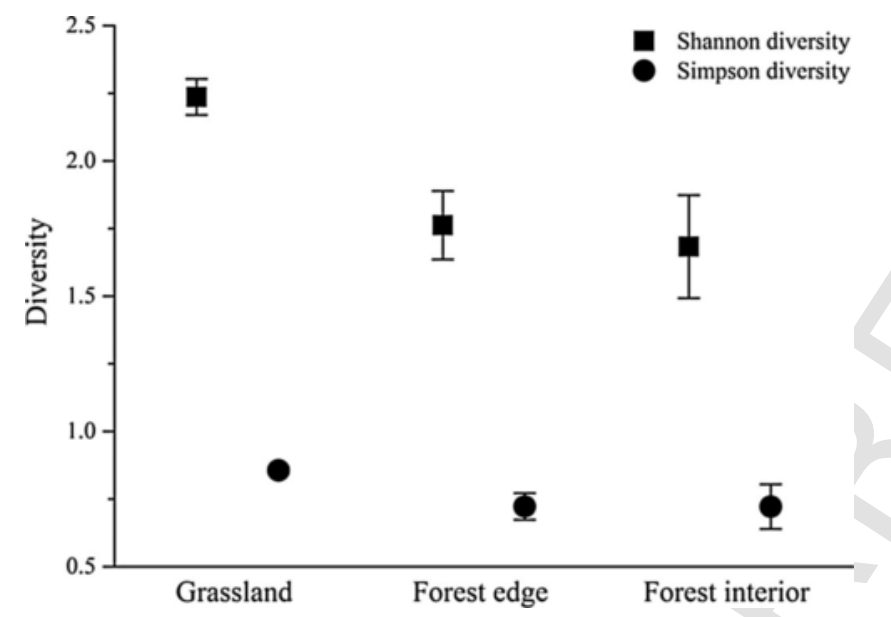

Fig. 2. Mean values of the Shannon and Simpson diversity $( \pm \mathrm{SD})$ across the studied edge gradient between native forest and natural grassland. Both diversity measures were significantly the highest in the grassland $(p<0.05)$, and there was no significant difference between the forest edge and the forest interior $(\mathrm{p}>0.05)$ by Tukey test.

The average phylogenetic distinctness was not significantly different (grassland: 78.41, edge: 77.28, forest interior: 75.85; Table S2). Non-significant increases in both the total species richness (Fig. 1) and the average phylogenetic distinctness in the forest edge compared to the interior, in combination, caused significant differences in the phylogenetic diversity, which decreased from the grassland towards the forest interior (Fig. 3 and Table S2).

The trend in the functional-phylogenetic diversity patterns was similar to those shown by the functional and phylogenetic diversities, and the functional-phylogenetic diversity also decreased from the grassland towards the forest interior (Fig. 3 and Table S2).

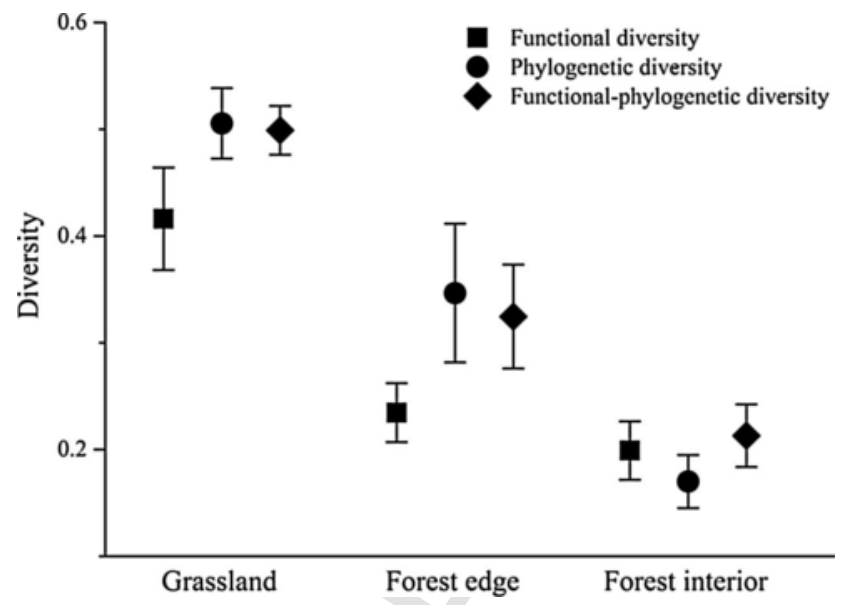

Fig. 3. Mean values of the functional, phylogenetic and functional-phylogenetic diversity $( \pm \mathrm{SD})$ across the studied edge gradient between native forest and natural grassland All diversity measures decreased significantly from the grassland across the forest edge towards the forest interior $(\mathrm{p}<0.05$ by Tukey test).

\section{Discussion \\ 4.1. Taxonomic diversity}

European grasslands usually maintain more diverse ground beetle assemblages than closed forests (Boetzl et al., 2016; Brigić et al., 2014; Koivula et al., 2004; Lacasella et al., 2015; Magura, 2002; Roume et al., 2011). This study documented similar differences: both the total species richness and the diversity of ground beetles were higher in the studied grasslands than the forests (interior and edge). The small-scale dispersal of species from the surrounding habitat is an important factor influencing species diversity (Cook et al., 2002). Neighbouring habitat patches are not isolated from each other, and there often is dispersal between them. Some forest species can move from the forest interior into the grassland and similarly, open-habitat ground beetle species can disperse from the grassland towards the forest interior (Brigić et al., 2014; Koivula et al., 2004; Lacasella et al., 2015). In our study, the grasslands were more affected by dispersal from the adjacent forests than vice versa, since more forest species were found in the grassland than open-habitat species in the forest interior. Stronger dispersal is predicted from habitats with higher primary production into habitats with lower primary production (Oksanen, 1990). In the studied system, moderately dry grasslands are encompassed in a highly productive forest matrix. Asymmetrical dispersal of ground beetle species between open-habitat and neighbouring forest is documented (Boetzl et al., 2016; Brigić et al., 2014; Koivula et al., 2004; Lacasella et al., 2015; Roume et al., 2011). Asymmetrical species dispersal of ground beetles may also be linked to the differences in habitat structure and environmental parameters at the forest edges. Natural forest edges include characteristics of both neighbouring habitats. They have a dense herb layer, a moderately closed canopy layer, and a dense shrub and sapling layer (Forman and Godron, 1986). Due to this physiognomy, habitat structure and environmental conditions at forest edges maintained by natural processes tend to resemble to those in open-canopy forests. Consequently, forest species can cross the edges towards grasslands easier than open-habitat species can move in the other direction. The presence of both the open-habitat and the generalist species, as well as the frequent dispersal of forest species all contribute to the elevated species richness in grassland patches (Brigić et al., 2014; 
Koivula et al., 2004; Lacasella et al., 2015; Magura et al., 2001; Roume et al., 2011).

The orientation of forest edges has a major impact on the microclimate and vegetation structure, and can impact the strength or expression of edge effect (Murcia, 1995; Ries et al., 2004). In our study, edges faced eastwards, and during the hottest daytime hours, these edges were shaded. Consequently, for forest species, these east-facing edges may be easier to cross, while for open-habitat species they probably constitute a stronger barrier than south- or south-west-facing edges do. Therefore, edge orientation must be taken into account when studying the edge effect (Murcia, 1995; Ries et al., 2004).

The species richness and diversity (characterised by the Shannon and Simpson diversity indices) of ground beetles were somewhat (not significantly) higher at the forest edge compared to the interior. Earlier studies reported significantly higher taxonomic diversity at forest edges than interiors (Lacasella et al., 2015; Magura, 2002; Magura et al., 2001; Tóthmérész et al., 2014). This elevated taxonomic diversity was attributed to the presence of species from both adjoining habitats, as well as to edge-associated species. These edge-associated species either occur exclusively at forest edges, or they are more abundant there than in the neighbouring habitats (Lacasella et al., 2015; Magura et al., 2001). In the present study, the abundance of Carabus coriaceus and $C$. hortensis was almost three times higher at the forest edge than in the interior, supporting previous categorisation of these two as edge-associated species (Magura et al., 2001; Molnár et al., 2001). Another explanation for this abundance pattern could be that the forest-grassland edge contrast caused these individuals to move along the edges (Wood and Samways, 1991), and encountered traps, placed parallel with the edge, more frequently.

Species classifications according to their habitat associations are strongly context-dependent (Niemelä et al., 2007). The habitat affinity of east-central European ground beetles is rather well documented, and is based on field data (Hůrka, 1996). In this study, only one species showed different spatial pattern from what would have been predicted from their previous habitat affinity categorisation: Carabus arvensis, classified as forest species, was most abundant in the grassland patches of our study area.

\subsection{Functional and phylogenetic diversity}

Taxonomic diversity (species richness and species diversity) is the most commonly used diversity indicator and frequently used as a proxy for functional or phylogenetic diversity (Milder et al., 2008). However, the relationship between taxonomic vs. functional or phylogenetic diversities may be complex and inconsistent (Mayfield et al., 2005). In this study, functional and phylogenetic diversity responded more strongly to the edge effect than taxonomic diversity.

Generally, resource concentration, structural complexity and habitat heterogeneity promote colonization by a wider range of species (habitat heterogeneity hypothesis and the resource hypothesis, Blakely and Didham, 2010). Therefore, the present study hypothesised that a homogenous environment filters closely related species characterised by similar traits (small-sized, winged, herbivorous or omnivorous, xerophilous or mesophilous species with diurnal activity in the grassland and larger, flightless, nocturnal, predatory, and hygrophilous species in the forest interior), while the structurally complex, heterogeneous forest edge with ample resources was expected to provide more opportunities for lineages with dissimilar traits due to effective microhabitat and resource partitioning (Blakely and Didham, 2010; Kraft et al., 2015). Contrary to this expectation, neither functional nor phylogenetic clustering was found in the grassland. Both types of diversity were extremely influenced by the many forest species that dispersed into the grassland patches. Grasslands maintained few but speciose lineages of grassland-associated species, as well as dispersing forest species which were phylogenetically more distant and had dissimilar traits than grassland species, contributing to the high functional and phylogenetic diversity found there. As a result of asymmetrical species dispersal from the neighbouring habitats, fewer open-habitat and generalist species from the adjacent grassland moved into the forest edge, while forest interior-inhabiting species found it easier to disperse into the edge. Therefore, many forest species and few open-habitat and generalist species coexisted at the edge, contributing to the lower functional and phylogenetic diversity found there than in the grassland. Moreover, forest edge seems to operate as an impermeable filter for open-habitat and generalist species, inhibiting these species to penetrate into the interior (Strayer et al., 2003). Thus, the forest interior maintains closely related forest species characterised by similar traits, resulting in functional and phylogenetic clustering in the forest interior assemblage. The difference in functional and phylogenetic diversity of ground beetles between the forest edge and interior highlights the influence of forest edge on functional and phylogenetic diversity.

According to the structural heterogeneity hypothesis, vertical or horizontal vegetation structure is an important factor in shaping the composition and diversity of ground beetles (Brose, 2003). Architecturally complex vegetation offers microhabitats for oviposition, hibernation and resting, increases the hunting efficiency, widens the food spectrum, and the chance of escape from natural enemies (Brose, 2003). Species from the neighbouring habitats are likely to be attracted to edge habitats because of the microhabitat availability, the increase in quantity or quality of resources (Cadenasso et al., 2003a, 2003b; Saavedra et al., 2014), avoiding intra- or interspecific interactions (like concurrence and competition) and predation risk in their source habitat (McCollin, 1998). Therefore, natural forest edges promote the coexistence of unrelated and functionally dissimilar species, contributing to the higher functional and phylogenetic diversity in the edge than in the interior. Similar positive edge effect on functional diversity was previously demonstrated for birds (Barbaro et al., 2014; Saavedra et al., 2014). Moreover, the majority of previous studies show higher phylogenetic diversity at forest edges than interiors (for plants: Dodonov et al., 2014; Peralta et al., 2015; for native parasitoids: Peralta et al., 2015; for mammals: Luza et al., 2015). These papers concluded that habitat characteristics of the forest and grassland are blended near the forest edge, creating high structural complexity and heterogeneity, and allowing the co-occurrence of distantly related species, increasing the phylogenetic diversity (Dodonov et al., 2014; Luza et al., 2015; Peralta et al., 2015). However, Peralta et al. (2015) found non-significant difference in herbivore phylogenetic diversity across an edge gradient between native and plantation forests, while Santos et al. (2010) reported loss of tree phylogenetic diversity in forest edges in a hyper-fragmented landscape. These results also emphasise that edge influence could be different according to the edge type (Harper et al., 2015).

Functional-phylogenetic diversity is a useful measure for combining information provided by traits and phylogeny (Cadotte et al., 2013). In the present study, traits and phylogeny contributed equally to the functional-phylogenetic diversity (as the phylogenetic-weighting parameter, $a$, was set to 0.5 ; see Cadotte et al., 2013). However, functional-phylogenetic diversity could be calculated using other weighting parameter values, from $a=1$ to 0 . This way the relationship between functional-phylogenetic diversity and position along the forest-grassland gradient could be tested by systematically changing the phylogenetic-weighting parameter. The maximum variance explained over functional-phylogenetic diversity across an edge gradient (the highest $\mathrm{R}^{2}$ or pseudo- $\mathrm{R}^{2}$ in the models) and the correspond- 
ing value of phylogenetic-weighting parameter could be identified, indicating how much variability in the community structure can be explained by traits and how much by phylogenetic relatedness (Cadotte et al., 2013). This method may provide a new dimension in future studies on edge effect.

\section{Conclusions}

The results showed that by only looking at taxonomic diversity metrics (such as species richness and species diversity) and ignoring functional and phylogenetic features of the assemblages, the edge influence on ground beetle diversity across forest-grassland gradients was insignificant. However, significant edge effect on ground beetle assemblages was shown when functional, phylogenetic and functional-phylogenetic diversities were used. Therefore, the inclusion of functional and phylogenetic features of the assemblages may bring about important insights into the mechanisms behind edge responses.

The results also demonstrated that natural forest edges maintain species from both neighbouring habitats but also species characteristic of, and often restricted to, the edge. Species living at natural edges have diverse functional traits and belong to a variety of lineages, increasing the functional and phylogenetic diversity. High functional and phylogenetic diversity affect ecosystem properties that are directly relevant to ecosystem services (Cavender-Bares et al., 2009; Díaz et al., 2007; Gagic et al., 2015). Therefore, preserving and protecting natural forest edges, and preventing damage to their structure, composition and characteristics is a key task in conservation management.

\section{Acknowledgements}

I thank Tivadar Molnár for his help during the field and laboratory work, Béla Tóthmérész for discussions on the research topic, and Gábor Lövei for comments on the manuscript. The publication was supported by the SROP4.2.2.B15/1/KONV20150001 project, financed by the European Union and the European Social Fund.

\section{Appendix A. Supplementary material}

Supplementary data associated with this article can be found, in the online version, at http://dx.doi.org/10.1016/j.foreco.2016.10.056.

\section{References}

Apaza-Quevedo, A., Lippok, D., Hensen, I., Schleuning, M., Both, S., 2015. Elevation, topography, and edge effects drive functional composition of woody plant species in tropical montane forests. Biotropica 47, 449-458.

Baker, S.C., Halpern, C.B., Wardlaw, T.J., Crawford, R.L., Bigley, R.E., Edgar, G.J., Evans, S.A., Franklin, J.F., Jordan, G.J., Karpievitch, Y., Spies, T.A., Thomson, R.J., 2015. Short- and long-term benefits for forest biodiversity of retaining unlogged patches in harvested areas. Forest Ecol. Manage. 353, 187-195.

Barbaro, L., Giffard, B., Charbonnier, Y., van Halder, I., Brockerhoff, E.G., 2014. Bird functional diversity enhances insectivory at forest edges: a transcontinental experiment. Divers. Distrib. 20, 149-159.

Barnes, A.D., Emberson, R.M., Chapman, H.M., Krell, F.-T., Didham, R.K., 2014 Matrix habitat restoration alters dung beetle species responses across tropical forest edges. Biol. Conserv. 170, 28-37.

Bates, D., Maechler, M., Bolker, B., Walker, S., 2015. Fitting linear mixed-effects models using lme4. J. Stat. Softw. 67, 1-48.

Benchimol, M., Peres, C.A., 2015. Edge-mediated compositional and functional decay of tree assemblages in Amazonian forest islands after 26 years of isolation. J. Ecol. 103, 408-420.

Benítez-Malvido, J., Gallardo-Vásquez, J.C., Alvarez-Añorve, M.Y., Avila-Cabadilla, L.D., 2014. Influence of matrix type on tree community assemblages along tropical dry forest edges. Am. J. Bot. 101, 820-829.

Beutel, R.G., Ribera, I., Bininda-Emonds, O.R.P., 2008. A genus-level supertree of Adephaga (Coleoptera). Org. Divers. Evol. 7, 255-269.
Blakely, T.J., Didham, R.K., 2010. Disentangling the mechanistic drivers of ecosystem-size effects on species diversity. J. Anim. Ecol. 79, 1204-1214.

Boetzl, F.A., Schneider, G., Krauss, J., 2016. Asymmetric carabid beetle spillover between calcareous grasslands and coniferous forests. J. Insect Conserv. 20, 49-57.

Bogyó, D., Magura, T., Nagy, D.D., Tóthmérész, B., 2015. Distribution of millipedes (Myriapoda, Diplopoda) along a forest interior - forest edge - grassland habitat complex. ZooKeys 510, 181-195.

Botta-Dukát, Z., 2005. Rao's quadratic entropy as a measure of functional diversity based on multiple traits. J. Veg. Sci. 16, 533-540.

Brigić, A., Starčević, M., Hrašovec, B., Elek, Z., 2014. Old forest edges may promote the distribution of forest species in carabid assemblages (Coleoptera: Carabidae) in Croatian forests. Eur. J. Entomol. 111, 715-725.

Brose, U., 2003. Bottom-up control of carabid beetle communities in early successional wetlands: mediated by vegetation structure or plant diversity?. Oecologia $135,407-413$.

Cadenasso, M.L., Pickett, S.T.A., Weathers, K.C., Bell, S.S., Benning, T.L., Carreiro, M.M., Dawson, T.E., 2003. An interdisciplinary and synthetic approach to ecological boundaries. Bioscience 53, 717-722.

Cadenasso, M.L., Pickett, S.T.A., Weathers, K.C., Jones, C.G., 2003. A framework for a theory of ecological boundaries. Bioscience 53, 750-758.

Cadotte, M.W., Davies, T.J., Regetz, J., Kembel, S.W., Cleland, E., Oakley, T.H., 2010. Phylogenetic diversity metrics for ecological communities: integrating species richness, abundance and evolutionary history. Ecol. Lett. 13, 96-105.

Cadotte, M., Albert, C.H., Walker, S.C., 2013. The ecology of differences: assessing community assembly with trait and evolutionary distances. Ecol. Lett. 16, 1234-1244.

Cavender-Bares, J., Kozak, K.H., Fine, P.V.A., Kembel, S.W., 2009. The merging of community ecology and phylogenetic biology. Ecol. Lett. 12, 693-715.

Clements, F.E., 1905. Research Methods in Ecology. The University Publishing Company, Lincoln.

Cook, W.C., Lane, K.T., Foster, B.L., Holt, R.D., 2002. Island theory, matrix effects and species richness patterns in habitat fragments. Ecol. Lett. 5, 619-623.

Debastiani, V.J., Pillar, V.D., 2012. SYNCSA - R tool for analysis of metacommunities based on functional traits and phylogeny of the community components. Bioinformatics 28, 2067-2068.

Díaz, S., Lavorel, S., De Bello, F., Quetier, F., Grigulis, K., Robson, M., 2007. Incorporating plant functional diversity effects in ecosystem service assessments. Proc. Natl. Acad. Sci. USA 104, 20684-20689.

Digweed, S.C., Currie, C.R., Carcamo, H.A., Spence, J.R., 1995. Digging out the digging-in effect of pitfall traps: influences of depletion and disturbance on catches of ground beetles (Coleoptera: Carabidae). Pedobiologia 39, 561-576.

Dodonov, P., da Silva, D.M., Rosatti, N.B., 2014. Understorey vegetation gradient in a Eucalyptus grandis plantation between a savanna and a semideciduous forest. N. Z . J. Forest. Sci. 44, 10.

D’Orazio, M., Di Zio, M., Scanu, M., 2006. Statistical Matching, Theory and Practice. Wiley, Chichester.

Ewers, R.M., Didham, R.K., 2006. Continuous response functions for quantifying the strength of edge effects. J. Appl. Ecol. 43, 527-536.

Filgueiras, B.K.C., Tabarelli, M., Leal, I.R., Vaz-de-Mello, F.Z., Iannuzzi, L., 2015 Dung beetle persistence in human-modified landscapes: combining indicator species with anthropogenic land use and fragmentation-related effects. Ecol. Indic. $55,65-73$.

Forman, R.T.T., Godron, M., 1986. Landscape Ecology. Wiley \& Sons, New York

Gagic, V., Bartomeus, I., Jonsson, T., Taylor, A., Winqvist, C., Fischer, A., Slade, E.M., Steffan-Dewenter, I., Emmerson, M., Potts, S., Tscharntke, T., Weisser, W., Bommarco, R., 2015. Functional identity and diversity of animals predict ecosystem functioning better than species-based indices. Proc. Roy. Soc. B-Biol. Sci. 282, 20142620.

Gerisch, M., 2014. Non-random patterns of functional redundancy revealed in ground beetle communities facing an extreme flood event. Funct. Ecol. 28, 1504-1512.

Gerlach, J., Samways, M., Pryke, J., 2013. Terrestrial invertebrates as bioindicators: an overview of available taxonomic groups. J. Insect Conserv. 17, 831-850.

Hansen, A.J., Risser, P.G., di Castri, F., 1992. Epilogue: Biodiversity and ecological flows across ecotones. In: Hansen, A.J., di Castri, F. (Eds.), Landscape Boundaries. Consequences for Biotic Diversity and Ecological Flows. Springer-Verlag, New York, pp. 423-438.

Harper, K.A., Macdonald, S.E., Burton, P.J., Chen, J., Brosofske, K.D., Saunders, S.C., Euskirchen, E.S., Roberts, D., Jaiteh, M.S., Esseen, P.-A., 2005. Edge influence on forest structure and composition in fragmented landscapes. Conserv. Biol. 19, 768-782.

Harper, K.A., Macdonald, S.E., Mayerhofer, M.S., Biswas, S.R., Esseen, P.-A., Hylander, K., Stewart, K.J., Mallik, A.U., Drapeau, P., Jonsson, B.-G., Lesieur, D., Kouki, J., Bergeron, Y., 2015. Edge influence on vegetation at natural and anthropogenic edges of boreal forests in Canada and Fennoscandia. J. Ecol. 103, 550-562.

Heikkala, O., Seibold, S., Koivula, M., Martikainen, P., Müller, J., Thorn, S., Kouki, J., 2016. Retention forestry and prescribed burning result in functionally different saproxylic beetle assemblages than clear-cutting. Forest Ecol. Manage. $359,51-58$.

Hůrka, K., 1996. Carabidae of the Czech and Slovak Republics. Kabourek, Zlin. 
Izsák, J., Papp, L., 2000. A link between ecological diversity indices and measures of biodiversity. Ecol. Model. 130, 151-156.

Kleyer, M., Dray, S., de Bello, F., Leps, J., Pakeman, R.J., Strauss, B., Thuiller, W., Lavorel, S., 2012. Assessing species and community functional responses to environmental gradients: which multivariate methods?. J. Veg. Sci. 23, 805-821.

Koch, K., 1989. Die Käfer Mitteleuropas. Ökologie. Goecke \& Evers Verlag, Krefeld.

Koivula, M., Hyyryläinen, V., Soininen, E., 2004. Carabid beetles (Coleoptera: Carabidae) at forest-farmland edges in southern Finland. J. Insect Conserv. 8, 297-309.

Kraft, N.J.B., Adler, P.B., Godoy, O., James, E.C., Fuller, S., Levine, J.M., 2015. Community assembly, coexistence and the environmental filtering metaphor. Funct. Ecol. 29, 592-599.

Lacasella, F., Gratton, C., De Felici, S., Isaia, M., Zapparoli, M., Marta, S., Sbordoni, V., 2015. Asymmetrical responses of forest and "beyond edge" arthropod communities across a forest-grassland ecotone. Biodivers. Conserv. 24, 447-465.

Laliberte, E., Legendre, P., 2010. A distance-based framework for measuring functional diversity from multiple traits. Ecology 91, 299-305.

Laliberte, E., Wells, J.A., DeClerck, F., Metcalfe, D.J., Catterall, C.P., Queiroz, C., Aubin, I., Bonser, S.P., Ding, Y., Fraterrigo, J.M., McNamara, S., Morgan, J.W., Merlos, D.S., Vesk, P.A., Mayfield, M.M., 2010. Land-use intensification reduces functional redundancy and response diversity in plant communities. Ecol. Lett. 13, 76-86.

Langhans, S.D., Tockner, K., 2014. Edge effects are important in supporting beetle biodiversity in a gravel-bed river floodplain. PLoS ONE 9, e114415.

Larochelle, A., 1990. The food of carabid beetles (Coleoptera: Carabidae, including Cicindelinae). Fabreries (Supplément 5), 1-132.

Lövei, G.L., Magura, T., Tóthmérész, B., Ködöböcz, V., 2006. The influence of matrix and edges on species richness patterns of ground beetles (Coleoptera, Carabidae) in habitat islands. Glob. Ecol. Biogeogr. 15, 283-289.

Luza, A.L., Gonçalves, G.L., Hartz, S.M., 2015. Phylogenetic and morphological relationships between nonvolant small mammals reveal assembly processes at different spatial scales. Ecol. Evol. 5, 889-902.

Ma, M., Herzon, I., 2014. Plant functional diversity in agricultural margins and fallow fields varies with landscape complexity level: conservation implications. J. Nat. Conserv. 22, 525-531.

Mader, H.J., 1984. Animal habitat isolation by roads and agricultural fields. Biol. Conserv. 29, 81-96

Magura, T., 2002. Carabids and forest edge: spatial pattern and edge effect. Forest Ecol. Manage. 157, 23-37.

Magura, T., Bogyó, D., Mizser, Sz., Nagy, D.D., Tóthmérész, B., 2015. Recovery of ground-dwelling assemblages during reforestation with native oak depends on the mobility and feeding habits of the species. Forest Ecol. Manage. 339, 117-126.

Magura, T., Tóthmérész, B., Molnár, T., 2001. Forest edge and diversity: carabids along forest-grassland transects. Biodivers. Conserv. 10, 287-300.

Magurran, A.E., 2004. Measuring Biological Diversity. Blackwell Publishing, Oxford

McCollin, D., 1998. Forest edges and habitat selection in birds: a functional approach. Ecography 21, 247-260.

Mayfield, M.M., Boni, M.E., Daily, G.C., Ackerly, D., 2005. Species and functional diversity of native and human-dominated plant communities. Ecology $86,2365-2372$

Milder, J.C., Lassoie, J.P., Bedford, B.L., 2008. Conserving biodiversity and ecosystem function through limited development: an empirical evaluation. Conserv. Biol. 22, 70-79.

Molnár, T., Magura, T., Tóthmérész, B., Elek, Z., 2001. Ground beetles (Carabidae) and edge effect in oak-hornbeam forest and grassland transects. Eur. J. Soil Biol. 37, 297-300.

Murcia, C., 1995. Edge effects in fragmented forests - implications for conservation. Trends Ecol. Evol. 10, 58-62.

Niemelä, J., Koivula, M., Kotze, J.D., 2007. The effects of forestry on carabid beetles (Coleoptera: Carabidae) in boreal forests. J. Insect Conserv. 11, 5-18.

Odum, E.P., 1971. Fundamentals of Ecology. Saunders, London.

Ohwaki, A., Kaneko, Y., Ikeda, H., 2015. Seasonal variability in the response of ground beetles (Coleoptera: Carabidae) to a forest edge in a heterogeneous agricultural landscape in Japan. Eur. J. Entomol. 112, 135-144.

Oksanen, T., 1990. Exploitation ecosystems in heterogeneous habitat complexes. Evol. Ecol. 4, 220-234.
Peralta, G., Frost, C.M., Didham, R.K., Varsani, A., Tylianakis, J.M., 2015. Phylogenetic diversity and co-evolutionary signals among trophic levels change across a habitat edge. J. Anim. Ecol. 84, 364-372.

Rao, C.R., 1982. Diversity and dissimilarity coefficients: a unified approach. Theor. Popul. Biol. 21, 24-43.

R Core Team, 2013. R: A Language and Environment. R Foundation, Vienna.

Ries, L., Fletcher, R.J., Battin, J., Sisk, T.D., 2004. Ecological responses to habitat edges: mechanisms, models, and variability explained. Annu. Rev. Ecol. Evol. Syst. 35, 491-522.

Roume, A., Deconchat, M., Raison, L., Balent, G., Ouin, A., 2011. Edge effects on ground beetles at the woodlot-field interface are short-range and asymmetrical. Agric. For. Entomol. 13, 395-403.

Saavedra, F., Hensen, I., Beck, S.G., Böhning-Gaese, K., Lippok, D., Töpfer, T., Schleuning, M., 2014. Functional importance of avian seed dispersers changes in response to human-induced forest edges in tropical seed-dispersal networks. Oecologia 176, 837-848.

Santos, B.A., Arroyo-Rodríguez, V., Moreno, C.E., Tabarelli, M., 2010. Edge-related loss of tree phylogenetic diversity in the severely fragmented Brazilian Atlantic forest. PLoS ONE 5, e12625.

Sarthou, J.-P., Badoz, A., Vaissière, B., Chevallier, A., Rusch, A., 2014. Local more than landscape parameters structure natural enemy communities during their overwintering in semi-natural habitats. Agric. Ecosyst. Environ. 194, 17-28.

Saunders, D.A., Hobbs, R.J., Margules, C.R., 1991. Biological consequences of ecosystem fragmentation: a review. Conserv. Biol. 5, 18-32.

Schluter, D., 2000. Ecological character displacement in adaptive radiation. Am. Nat. 156, S4-S16.

Spake, R., Barsoum, N., Newton, A.C., Doncaster, C.P., 2016. Drivers of the composition and diversity of carabid functional traits in UK coniferous plantations. Forest Ecol. Manage. 359, 300-308.

Strayer, D.L., Power, M.E., Fagan, W.F., Pickett, S.T.A., Belnap, J., 2003. A classification of ecological boundaries. Bioscience 53, 723-729.

Swenson, N.G., 2011. The role of evolutionary processes in producing biodiversity patterns, and the interrelationships between taxonomic, functional and phylogenetic biodiversity. Am. J. Bot. 98, 472-480.

Swenson, N.G., 2013. The assembly of tropical tree communities - the advances and shortcomings of phylogenetic and functional trait analyses. Ecography $36,264-276$.

Taboada, A., Kotze, D.J., Salgado, J.M., 2004. Carabid beetle occurrence at the edges of oak and beech forests in NW Spain. Eur. J. Entomol. 101, 555-563.

Tóthmérész, B., Nagy, D.D., Mizser, Sz., Bogyó, D., Magura, T., 2014. Edge effects on ground-dwelling beetles (Carabidae and Staphylinidae) in oak forest-forest edge-grassland habitats in Hungary. Eur. J. Entomol. 111, 686-691.

Tucker, C.M., Cadotte, M.W., Carvalho, S.B., Davies, T.J., Ferrier, S., Fritz, S.A., Grenyer, R., Helmus, M.R., Jin, L.S., Mooers, A.O., Pavoine, S., Purschke, O., Redding, D.W., Rosauer, D.F., Winter, M., Mazel, F., 2016. A guide to phylogenetic metrics for conservation, community ecology and macroecology. Biol. Rev. 91 , in press

Turner, M.G., Gardner, R.H., O’Neill, R.V., 2001. Landscape Ecology in Theory and Practice: Pattern and Process. Springer Verlag, New York.

Vandewalle, M., de Bello, F., Berg, M.P., Bolger, T., Doledec, S., Dubs, F., Feld, C.K., Harrington, R., Harrison, P.A., Lavorel, S., da Silva, P.M., Moretti, M., Niemelä, J., Santos, P., Sattler, T., Sousa, J.P., Sykes, M.T., Vanbergen, A.J., Woodcock, B.A., 2010. Functional traits as indicators of biodiversity response to land use changes across ecosystems and organisms. Biodivers. Conserv. 19, 2921-2947.

Violle, C., Navas, M.L., Vile, D., Kazakou, E., Fortunel, C., Hummel, I., Garnier, E., 2007. Let the concept of trait be functional!. Oikos $116,882-892$.

Webb, C.O., Ackerly, D.D., McPeek, M.A., Donoghue, M.J., 2002. Phylogenies and community ecology. Annu. Rev. Ecol. Syst. 33, 475-505.

Wood, P.A., Samways, M.J., 1991. Landscape element pattern and continuity of butterfly flight paths in an ecologically landscaped botanic garden, Natal, South Africa. Biol. Conserv. 58, 149-166.

Zuur, A., Ieno, E.N., Walker, N., Saveiliev, A.A., Smith, G.M., 2009. Mixed Effects Models and Extensions in Ecology with R. Springer, New York. 